\title{
Penentuan Jalur Rute Distribusi Produk Fast Moving Consumer Goods (FMCG) dengan Menggunakan Metode Nearest Neighbour (Studi Kasus: PT.XYZ)
}

\author{
Chendrasari Wahyu Oktavia ${ }^{1 *}$, Christine Natalia ${ }^{1}$, Indra Adigunawan $^{1}$ \\ ${ }^{1}$ Program Studi Teknik Industri, Fakultas Teknik, Univeristas Katolik Indonesia Atma Jaya, \\ Jl. Raya Cisauk-Lapan, Tangerang, 15345
}

Penulis untuk Korespondensi/E-mail: chendrasari@gmail.com

\begin{abstract}
Abstrak - PT. XYZ merupakan perusahaan logistik yang bergerak dalam pendistribusian produk ke seluruh area JABODETABEK. Dalam menjalankan aktivitas proses pendistribusian, perusahaan dihadapkan pada kondisi permasalahan yaitu perusahaan diharuskan untuk mengunjungi dan melayani konsumen dengan lokasi yang tersebar di area JABODETABEK dengan tetap memperhatikan kapasitas muatan dari armada dan rute yang dilalui kendaraan. Oleh karena itu, diperlukan penentuan rute yang tepat agar perusahaan dapat memenuhi pengiriman tepat waktu kepada konsumen. Dengan adanya masalah tersebut, penelitian ini bertujuan untuk melakukan optimasi rute kendaraan dengan metode nearest neighbor agar mampu meminimalisir total jarak, total waktu dan biaya distribusi yang kemudian akan dianalisa perbandingan data aktual dan nearest neighbor. Pada penelitian ini menggunakan metode nearest neighbor. Hasil yang didapatkan dari penelitian ini adalah: (1) Mampu mengurangi persentase rata-rata jarak tempuh kendaraan dalam bulan Oktober 2018 sebesar $27 \%$ atau $44,09 \mathrm{~km}$ tiap harinya, (2) Mengurangi total waktu tempuh 157 menit dari data aktual, (3) Mampu menghemat total biaya sebesar 15\% atau Rp. 53,458 tiap harinya. Dengan demikian metode pendekatan nearest neighbor mampu mengurangi biaya distribusi yang dikeluarkan oleh perusahaan tiap bulan.
\end{abstract}

Abstract-PT. XYZ is a logistics company engaged in the distribution of products throughout the Greater Jakarta area. In carrying out the distribution process activities, the company is faced with the requirements of the problem about the company required to provide information and serve consumers with locations scattered in the Greater Jakarta area with due regard to capacity of vehicle and route. Therefore, it is necessary to determine the right route so that companies can meet timely deliveries to consumers. Given these problems, this study aims to optimize vehicle routes with the nearest neighbor method so as to minimize the time and cost of distribution which will then be analyzed to analyze the actual data and the nearest neighbors. In this study using the nearest neighbor method. The results obtained from this study are: (1) Able to reduce the average percentage of vehicle mileage in October 2018 by $27 \%$ or $44,09 \mathrm{~km}$ per shipment. (2) reduce total travel time of 157 minute from actual data, (3) Able to increase total costs by $15 \%$ or $\mathbf{R p . 5 3 , 4 5 8}$. Thus, the method of taking the nearest neighbor can reduce the distribution costs incurred by the company each month.

Keywords - Distribution cost, Nearest neighbor, Route determination

\section{PENDAHULUAN}

$\mathrm{P}$ engiriman yang tepat waktu dengan jumlah serta spesifikasi yang tepat merupakan salah satu faktor terpenting dalam memenuhi permintaan konsumen saat ini. Oleh karena itu, diperlukan penentuan rute pendistribusian yang tepat. Proses pendistribusian yang tepat dapat meminimalisir biaya yang dikeluarkan oleh perusahaan. Hal ini sejalan dengan pernyataan [1] yang menyatakan bahwa kesalahan dalam pengambilan keputusan untuk menentukan lokasi akan berakibat pada besarnya biaya dan menurunkan daya saing perusahaan di mata konsumen.

Secara umum, permasalahan dalam penentuan rute masuk ke dalam permasalahan Vehicle Routing Problem (VRP). Dalam permasalahan VRP 
merupakan permasalahan distribusi untuk mencari serangkaian rute dengan ongkos seminimal mungkin untuk sejumlah kendaraan tertentu dengan kapasitas tertentu dari suatu depot ke pelanggan yang letak lokasinya tersebar dengan jumlah permintaan yang tidak sama. Sebuah rute dalam VRP merupakan serangkaian lokasi yang harus dikunjugi kendaraan pengangkut untuk menyelesaikan pengantaran produk.

Menurut [2], VRP memiliki tujuan meminimasi biaya transportasi, meminimasi jumlah kendaraan, menyeimbangkan rute serta muatan kendaraan, dan meminimasi penalti yang diakibatkan terlambatnya pengiriman ke pelanggan. Berdasarkan tujuan tersebut, maka ada beberapa karakteristik dalam VRP yaitu depot, armada, rute kendaraan, dan pelanggan. Menurut [3], penyelesaian VRP menghasilkan rute dan penjadwalan kendaraan pengangkut dalam rute yang telah terbentuk.

Salah satu solusi untuk memecahkan persoalan VRP dengan menggunakan nearest neighbour, dimana metode ini akan melakukan pencarian pelanggan terdekat dengan pelanggan selanjutnya sampai didapatkan pelanggan terakhir untuk rute yang dilalui. Rute baru dimulai melalui cara yang sama apabila tidak terdapat posisi yang fisibel untuk menempatkan pelanggan baru karena kendala kapasitas atau time windows [4]. Menurut [5] menjelaskan bahwa menentukan rute terpendek sehingga jalur distribusi dapat dilakukan secara optimal yang mana optimal disini adalah jumlah barang yang dikirim, waktu pengiriman, dan jarak yang dibutuhkan tepat. Metode nearest neighbour juga melibatkan faktor biaya dalam pendistribusian ke masing-masing lokasi yang mana biaya transportasi yang terlibat adalah biaya tetap dan biaya variabel.

PT. XYZ merupakan perusahaan yang bergerak di bidang logistik yang mengirimkan sejumlah produk ke lokasi konsumen yang tersebar di area JABODETABEK. Sebagai penyedia jasa logistik, tentunya perusahaan ini dituntut untuk mengirimkan sejumlah produk dengan waktu pengiriman, jumlah, dan spesifikasi produk yang tepat.

Permasalahan yang terdapat dalam ruang lingkup proses pendistribusian produk pada PT. XYZ adalah menentukan rute distribusi yang tepat agar dapat meminimalkan biaya distribusi barang ke pelanggan serta waktu pengiriman. Namun, dalam permasalahan proses pendistribusian juga perlu memperhatikan batas waktu pengiriman, lokasi konsumen, jumlah permintaan konsumen, rute pengiriman, dan kapasitas kendaraan

Pada bulan Oktober untuk proses pendistribusian produk, perusahaan melayani 18 konsumen seperti pada Tabel 1. dengan lokasi yang tersebar di area di JABODETABEK dimana saat ini perusahaan masih memiliki satu titik depot dan satu armada. Dengan kapasitas daya angkut armada maksimal adalah 5 ton atau 72 Box.

Tabel 1. Jumlah Konsumen

\begin{tabular}{cl}
\hline Kode & \multicolumn{1}{c}{ Alamat } \\
\hline T1 & J1. Mangga 7, Kb. Jeruk, Jakarta. \\
\hline T2 & J1. Gelora No. 2, Tanahabang, Jakarta. \\
\hline T3 & J1. Tegal Rotan, Tangerang. \\
\hline T4 & J1. Alternatif Cibubur, Depok, Jawa Barat. \\
\hline T5 & J1. Dato Tonggara, Kramat Jati, Jakarta. \\
\hline T6 & J1. Panti Asuhan, Tangerang Selatan, Tangerang. \\
\hline T7 & J1. H. Kamang, Cilandak, Jakarta. \\
\hline T8 & J1. Joglo Raya, Kembangan, Jakarta. \\
\hline T9 & J1. Raya Tiong, Setiabudi, Jakarta. \\
\hline T10 & Ruko Taman Grisenda, Penjaringan, Jakarta. \\
\hline T11 & Komp. Duta Harapan Indah, Kapuk Muara, Jakarta. \\
\hline T12 & J1. Boulevard Raya, Kelapa Gading, Jakarta. \\
\hline T13 & J1. Biru Laut III, Jatinegara, Jakarta. \\
\hline T14 & J1. Raya Kp. Sawah, Bekasi, Jawa Barat. \\
\hline T15 & Ruko Mega Grosir Cempaka Mas, Kemayoran, Jakarta. \\
\hline T16 & J1. Kramat Raya, Senen, Jakarta. \\
\hline T17 & J1. Gg. Mando, Ciputat, Tangerang Selatan. \\
\hline T18 & J1. Raya Kalibata, Pancoran, Jakarta. \\
\hline T9 & J1. Raya Tiong, Setiabudi, Jakarta. \\
\hline T10 & Ruko Taman Grisenda, Penjaringan, Jakarta. \\
\hline T11 & Komp. Duta Harapan Indah, Kapuk Muara, Jakarta. \\
\hline T12 & J1. Boulevard Raya, Kelapa Gading, Jakarta. \\
\hline T13 & J1. Biru Laut III, Jatinegara, Jakarta. \\
\hline T14 & J1. Raya Kp. Sawah, Bekasi, Jawa Barat. \\
\hline T15 & Ruko Mega Grosir Cempaka Mas, Kemayoran, Jakarta. \\
\hline T16 & J1. Kramat Raya, Senen, Jakarta. \\
\hline T17 & J1. Gg. Mando, Ciputat, Tangerang Selatan. \\
\hline T18 & J1. Raya Kalibata, Pancoran, Jakarta. \\
\hline & \\
\hline
\end{tabular}

Dalam menentukan urutan distribusi saat ini berdasarkan pengalaman dari supir dan kernet. Hal inilah yang menyebabkan kurang maksimalnya waktu pendistribusian dari produk ke pelanggan sehingga biaya distribusi menjadi besar.

Dari 18 lokasi tersebut, selama bulan Oktober 2018 total jarak tempuh bervariasi dari lokasi awal ke lokasi akhir seperti terlihat pada Tabel 2 di bawah ini

Tabel 2. Total Jarak Tempuh

\begin{tabular}{cc}
\hline Tanggal & Total Jarak Tempuh $(\mathrm{km})$ \\
\hline 1 & 126,84 \\
2 & 180,18 \\
3 & 208,91 \\
4 & 146,15 \\
5 & 164,17 \\
\hline
\end{tabular}




\begin{tabular}{cc}
\hline Tanggal & Total Jarak Tempuh $(\mathrm{km})$ \\
\hline 6 & 172,57 \\
8 & 150,81 \\
9 & 190,17 \\
10 & 189,82 \\
11 & 162,46 \\
12 & 119,40 \\
13 & 185,17 \\
15 & 177,79 \\
16 & 155,39 \\
17 & 185,11 \\
18 & 181,30 \\
19 & 147,00 \\
20 & 224,03 \\
22 & 146,23 \\
23 & 183,93 \\
24 & 168,95 \\
25 & 141,35 \\
26 & 153,31 \\
27 & 192,05 \\
29 & 159,03 \\
30 & 160,50 \\
31 & 146,58 \\
& \\
\hline
\end{tabular}

Tujuan dari penelitian ini adalah melakukan optimasi rute kendaraan dengan metode nearest neighbor agar mampu meminimalisir waktu, total jarak yang ditempuh dan biaya distribusi yang kemudian akan dianalisa perbandingan data aktual dan nearest neighbor.

\section{METODE}

\section{Desain, tempat dan waktu}

Penelitian ini dilakukan dengan pengumpulan data baik yang diperoleh dari hasil wawancara dan observasi. Data-data yang diperlukan dalam penelitian ini adalah data yang telah berhasil dikumpulkan dari perusahaan seperti data rute distribusi awal, kapasitas armada, jumlah permintaan konsumen, jarak ke lokasi pelanggan, waktu, biaya transportasi dan jumlah konsumen. Data yang dikumpulkan merupakan data selama bulan Oktober pada tahun 2018. Berdasarkan datadata yang telah dikumpulkan, selanjutnya mengolah ke dalam nearest neighbour, berdasarkan hasil dari metode nearest neighbour akan membantu dalam memberikan usulan perbaikan model distribusi

\section{Jenis dan cara pengumpulan data (survei)/tahapan penelitian}

Data yang dikumpulkan dalam penelitian ini adalah data selama bulan Oktober meliputi data rute distribusi awal, kapasitas armada, jumlah permintaan konsumen, jarak ke lokasi pelanggan, waktu, biaya transportasi dan jumlah konsumen dimana data-data ini diperoleh dari hasil wawancara dan observasi dengan pihak perusahaan.

\section{Pengolahan dan Analisis data}

Data yang terkumpul, kemudian data tersebut dilakukan pengolahan menggunakan metode nearest neighbor. Metode nearest neighbor merupakan algoritma yang mudah untuk diimplementasikan dan dilakukan. Pada algoritma ini, hanya pergi ke pelanggan dengan jarak yang terdekat yang belum dikunjungi dengan menyertakan beberapa batasan. Berikut ini merupakan langkah-langkah yang harus dilakukan dalam pengerjaan pembentukan rute dengan menggunakan metode nearest neighbor:

1) Memilih titik pusat sebagai titik awal pengiriman.

2) Menentukan titik dengan jarak terkecil dari gudang titik awal, yang selanjutnya adalah melakukan penggabungan antar kedua titik tersebut.

3) Titik yang terakhir dikunjungi menjadi titik awal, dan selanjutnya mencari titik dengan jarak terdekat dari titik awal tersebut.

4) Lakukan proses pengulangan sampai dengan kapasitas kendaraan sudah tidak mencukupi untuk melakukan pengiriman.

5) Tarik titik tersebut pada satu garis, titik tersebut merupakan satu rute perjalanan, dengan kapasitas kendaraan sebagai kendala dalam pembentukan satu rute perjalanan pengiriman barang.

6) Lakukan proses yang sama, pada langkah satu sampai dengan langkah lima.

Hasil dari pengolahan metode nearest neighbor akan didapatkan jalur rute terbaru. Hasil dari rute terbaru ini akan dibandingkan dengan rute kondisi awal sehingga dari rute kondisi terbaru akan diperoleh informasi jarak, waktu pengiriman, dan penghematan biaya transportasi.

\section{HASIL DAN PEMBAHASAN}

\section{Wilayah Distribusi}

Total jumlah pelanggan yang dilayani oleh perusahaan PT. XYZ sebanyak 18 pelanggan dengan lokasi tersebar di area JABODETABEK seperti yang terlihat pada Tabel 3 . 
Tabel 3. Jumlah Pelanggan

\begin{tabular}{cl}
\hline Kode & \multicolumn{1}{c}{ Alamat } \\
\hline T1 & J1. Mangga 7, Kb. Jeruk, Jakarta. \\
\hline T2 & J1. Gelora No. 2, Tanahabang, Jakarta. \\
\hline T3 & J1. Tegal Rotan, Tangerang. \\
\hline T4 & J1. Alternatif Cibubur, Depok, Jawa Barat. \\
\hline T5 & J1. Dato Tonggara, Kramat Jati, Jakarta. \\
\hline T6 & J1. Panti Asuhan, Tangerang Selatan, Tangerang. \\
\hline T7 & J1. H. Kamang, Cilandak, Jakarta. \\
\hline T8 & J1. Joglo Raya, Kembangan, Jakarta. \\
\hline T9 & J1. Raya Tiong, Setiabudi, Jakarta. \\
\hline T10 & Ruko Taman Grisenda, Penjaringan, Jakarta. \\
\hline T11 & Komp. Duta Harapan Indah, Kapuk Muara, Jakarta. \\
\hline T12 & J1. Boulevard Raya, Kelapa Gading, Jakarta. \\
\hline T13 & J1. Biru Laut III, Jatinegara, Jakarta. \\
\hline T14 & J1. Raya Kp. Sawah, Bekasi, Jawa Barat. \\
\hline T15 & Ruko Mega Grosir Cempaka Mas, Kemayoran, Jakarta. \\
\hline T16 & J1. Kramat Raya, Senen, Jakarta. \\
\hline T17 & J1. Gg. Mando, Ciputat, Tangerang Selatan. \\
\hline T18 & J1. Raya Kalibata, Pancoran, Jakarta. \\
\hline T9 & J1. Raya Tiong, Setiabudi, Jakarta. \\
\hline T10 & Ruko Taman Grisenda, Penjaringan, Jakarta. \\
\hline T11 & Komp. Duta Harapan Indah, Kapuk Muara, Jakarta. \\
\hline T12 & J1. Boulevard Raya, Kelapa Gading, Jakarta. \\
\hline T13 & J1. Biru Laut III, Jatinegara, Jakarta. \\
\hline T14 & J1. Raya Kp. Sawah, Bekasi, Jawa Barat. \\
\hline T15 & Ruko Mega Grosir Cempaka Mas, Kemayoran, Jakarta. \\
\hline T16 & J1. Kramat Raya, Senen, Jakarta. \\
\hline T17 & J1. Gg. Mando, Ciputat, Tangerang Selatan. \\
\hline T18 & J1. Raya Kalibata, Pancoran, Jakarta. \\
\hline
\end{tabular}

Perusahaan PT. XYZ, saat ini memiliki satu depot dimana depot ini merupakan titik awal pengiriman produk ke pelanggan. Armada angkut akan mengirimkan sejumlah produk ke pelanggan sesuai dengan jumlah permintaan yang dibutuhkan oleh pelanggan. Setiap pelanggan memiliki jumlah kebutuhan permintaan berbeda-beda yang mana dalam setiap pendistribusiannya armada yang ditugaskan untuk mengantarkan produk ke pelanggan memiliki keterbatasan dalam kapasitas muatan.

Berdasarkan Tabel 3. menunjukkan perusahaan PT. XYZ melayani 18 lokasi pelanggan di area JABODETABEK dimana 4 lokasi pelanggan berada di Tangerang, 1 lokasi pelanggan di Depok, dan sebagian besar lokasi berada di Jakarta. Lokasi yang tersebar di beberapa lokasi berbeda menyebabkan kesulitan bagi supir dan kernet untuk menentukan jalur distribusi yang tepat.

Armada yang ditugaskan akan harus mengirimkan sejumlah produk dari titik depot kemudian di distribusikan dari satu pelanggan ke pelanggan lain, seperti terlihat pada Gambar 1 yakni jalur rute distribusi dari Depot ke Pelanggan.

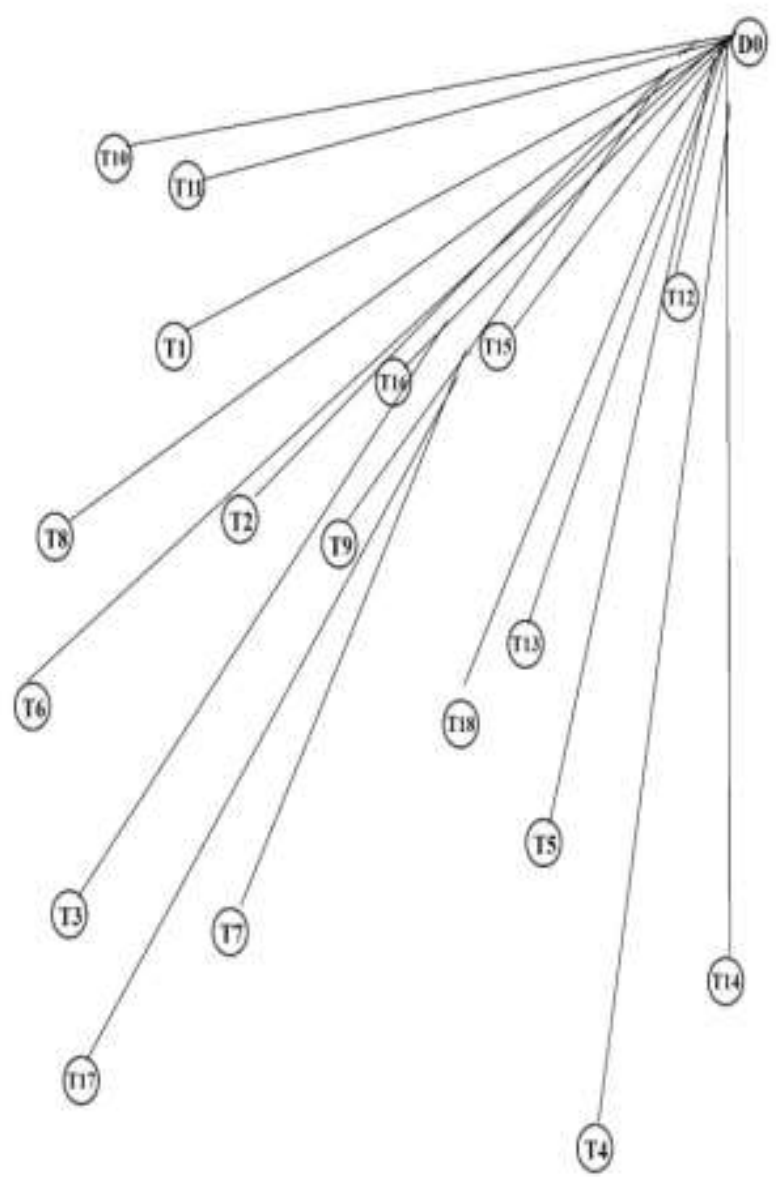

Gambar 1. Jalur Rute distribusi dari Depot ke Pelanggan

\section{Permintaan Pelanggan}

Permintaan pelanggan merupakan jumlah kebutuhan pelanggan yang harus dipenuhi oleh perusahaan sehingga dalam setiap kali pengiriman ke pelanggan. Namun, dalam memenuhi permintaan pelanggan perusahaan dihadapkan pada kapasitas muatan armada. Armada yang dimiliki oleh perusahaan PT. XYZ memiliki daya angkut maksimal adalah 5 ton atau muat 72 box. Dalam pengiriman setiap harinya, jumlah box yang dikirim berbeda - beda. Dalam bulan Oktober, total permintaan yang dikirim ke pelanggan sebanyak 1856 box. Dimana pada tanggal tertentu pada bulan Oktober, perusahaan PT. XYZ mengirimkan 72 box, 65 box, dan 60 box ke pelanggan seperti terlihat pada Tabel 4. Perbedaan ini dikarenakan perubahan permintaan setiap pelanggan pada setiap harinya sehingga bisa dikatakan pada tanggal tertentu di bulan Oktober, jumlah pengiriman produk sesuai dengan standar kapasitas muatan armada yaitu 72 box atau 5 ton. 


\begin{tabular}{cc}
\multicolumn{2}{c}{ Tabel 4. Total Permintaan Pelanggan } \\
\hline Tanggal & Total Pe rmintaan (Box) \\
\hline 1 & 72 \\
2 & 69 \\
3 & 62 \\
4 & 67 \\
5 & 72 \\
6 & 70 \\
8 & 69 \\
9 & 70 \\
10 & 71 \\
11 & 71 \\
12 & 70 \\
13 & 68 \\
15 & 70 \\
16 & 65 \\
17 & 72 \\
18 & 70 \\
19 & 69 \\
20 & 70 \\
22 & 70 \\
23 & 70 \\
24 & 72 \\
25 & 71 \\
26 & 60 \\
27 & 66 \\
29 & 69 \\
30 & 62 \\
31 & 69 \\
\hline Total & $\mathbf{1 8 5 6}$ \\
\hline & \\
\hline
\end{tabular}

Tabel 4 merupakan jumlah permintaan pelanggan selama bulan Oktober. Pada tanggal 3 Oktober 2018, armada harus mengirimkan produk sesuai dengan permintaan pelanggan. Adapun pengirimannya untuk toko 4 , toko 5 , toko 8 , toko 10 , toko 14 , toko 17 .

\section{Armada dan Kapasitas}

Kendaraan atau armada yang digunakan yaitu berupa mobil box yang mampu mengangkut box yang berisikan produk FMCG sebanyak 72 Box.

\section{Waktu Bongkar-Muat Produk}

Pada proses bongkar-muat produk membutuhkan rata-rata waktu sebesar 13 detik/box untuk bongkar dari mobil box ke toko dan 7 detik /box untuk muat dari toko (box kosong) ke dalam mobil box.

\section{Biaya Variabel untuk Transportasi}

Biaya variabel yang dikeluarkan oleh perusahaan untuk proses pendistribusian berupa biaya BBM yaitu sebesar Rp. 643,75 /km. Dimana armadanya ini 1 liter bahan bakar akan habis setelah menempuh jarak perjalanan $8 \mathrm{~km}$.

\section{Biaya Tetap (Fix Cost)}

Fix cost yang dikeluarkan oleh perusahaan berupa biaya KIR, Biaya STNK, biaya Maintenance (pemeliharaan kendaraan) dan biaya gaji sopir.

Berikut ini Fix Cost yang harus dikeluarkan oleh perusahaan dalam pendistribusian:

1) Maintenance kendaraan sebesar Rp. 500.000,/Bulan.

2.) Gaji sopir dan kernet masing-masing Rp.4.900.00,- dan Rp. 1.300.000,- /Bulan.

3.) Biaya lembur sopir dan kernet masing-masing sebesar Rp. 40.000,- dan Rp. 20.000,- /jam.

\section{Upah Harian}

Pada proses pendistribusian dibutuhkan sopir dan kernet untuk menghantarkan permintaan konsumen berupa box produk FMCG. Jam kerja normal sopir adalah 8 jam kerja. Jika jam kerja melebihi waktu normal, maka diadakan waktu lembur untuk sopir dan kernet, Upah harian untuk sopir dan kernet perharinya yaitu masing-masing sebesar Rp. 181.481 dan Rp. 41.148 sedangkan biaya lembur untuk sopir sebesar Rp. 40.000 per jam dan biaya lembur kernet sebesar Rp. 20.000 per jam.

\section{Waktu Distribusi}

Total waktu yang digunakan pada saat proses pendistribusian adalah sebagai berikut:

1. Waktu muat produk dari gudang ke armada berupa mobil box dengan rata-rata 15 menit.

2. Waktu set-up mobil mengikuti waktu muat produk.

3. Waktu perjalanan $=$ jarak tempuh $(\mathrm{km})$ dibagi dengan kecepatan (Km/Jam).

4. Waktu pelayanan pelanggan $=$ (Jumlah box pesanan yang dikirim $\mathrm{x}$ Rata-rata angkut box FMCG dari armada menuju toko (13 detik/box)) + Jumlah box kosong dari toko x Rata-rata angkut box kosong FMCG menuju armada mobil box ( 7 detik /box).

5. Waktu total $=$ Waktu muat produk dari gudang ke armada mobil box + Waktu set-up mobil + Waktu perjalanan + Waktu pelayanan pelanggan.

\section{Pengolahan Data}

Pengolahan data dilakukan dengan metode nearest neighbor, pada pendekatan ini akan dilakukan perhitungan jarak, dan waktu, dan biaya. Pertamatama, menghitung data aktual waktu distribusi, lalu dibandingkan dengan data nearest neighbor.

\section{Data Aktual}

Data aktual ini adalah data berisikan total jarak yang ditempuh dari depot ke beberapa pelanggan dengan suatu rute serta lamanya waktu yang dibutuhkan. 
Penjabaran total jarak tempuh dan total waktu tempuh diperlihatkan pada Tabel 5.

Tabel 5. Data aktual jarak dan waktu tempuh

\begin{tabular}{|c|c|c|c|}
\hline Tanggal & Rute & $\begin{array}{c}\text { Total Jarak } \\
\quad(\mathbf{K m})\end{array}$ & $\begin{array}{c}\text { Total } \\
\text { Waktu } \\
\text { Tempuh }\end{array}$ \\
\hline 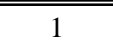 & 年-2-6-9-11-13-15-0 & 126,84 & 352,40 \\
\hline 2 & $0-1-3-7-12-16-17-0$ & 180,18 & 478,42 \\
\hline 3 & $0-4-5-8-10-14-17-0$ & 208,91 & 542,72 \\
\hline 4 & $0-2-6-7-10-13-15-0$ & 146,15 & 395,43 \\
\hline 5 & $0-1-3-9-11-12-18-0$ & 164,17 & 442,00 \\
\hline 6 & $0-4-5-7-8-14-16-0$ & 172,57 & 460,83 \\
\hline 8 & $0-2-6-8-9-14-16-0$ & 150,81 & 407,94 \\
\hline 9 & $0-1-3-5-10-14-18-0$ & 190,17 & 503,07 \\
\hline 10 & $0-4-6-11-14-15-16-0$ & 189,82 & 502,89 \\
\hline 11 & $0-7-12-13-16-17-18-0$ & 162,46 & 437,24 \\
\hline 12 & $0-1-3-8-10-11-15-0$ & 119,40 & 333,24 \\
\hline 13 & $0-4-5-9-12-14-17-0$ & 185,17 & 489,74 \\
\hline 15 & $0-2-6-8-10-13-17-0$ & 177,79 & 473,36 \\
\hline 16 & $0-1-3-7-9-14-16-0$ & 155,39 & 416,26 \\
\hline 17 & $0-4-6-11-15-17-18-0$ & 185,11 & 492,27 \\
\hline 18 & $0-2-5-8-12-13-17-0$ & 181,30 & 481,80 \\
\hline 19 & $0-1-3-7-9-10-16-0$ & 147,00 & 398,81 \\
\hline 20 & $0-4-6-8-14-15-17-0$ & 224,03 & 584,34 \\
\hline 22 & $0-2-5-9-11-12-13-0$ & 146,23 & 397,63 \\
\hline 23 & $0-1-3-7-10-16-17-0$ & 183,93 & 488,09 \\
\hline 24 & $0-4-6-9-14-15-18-0$ & 168,95 & 453,49 \\
\hline 25 & $0-2-5-8-10-11-13-0$ & 141,35 & 386,57 \\
\hline 26 & $0-1-3-9-10-12-16-0$ & 153,31 & 407,95 \\
\hline 27 & $0-4-5-7-11-15-17-0$ & 192,05 & 504,93 \\
\hline 29 & $0-2-6-8-12-14-18-0$ & 159,03 & 427,68 \\
\hline 30 & $0-1-3-7-9-10-13-0$ & 160,50 & 426,54 \\
\hline 31 & $0-4-5-12-13-15-18-0$ & 146,58 & 397,79 \\
\hline \multicolumn{2}{|r|}{ TOTAL } & 4.519 & 12.083 \\
\hline
\end{tabular}

Berdasarkan Tabel 5 di atas, data aktual untuk total waktu pengiriman pada bulan Oktober berbedabeda untuk setiap harinya. Pada tanggal 3 Oktober, waktu yang dibutuhkan untuk mengirimkan produk ke beberapa pelanggan sekitar 542,72 menit dengan total jarak yang ditempuh adalah $208,91 \mathrm{~km}$.

\section{Biaya Pendistribusian Aktual}

Setelah mendapatkan pengelompokan rute dan total jarak rute distribusi data aktual, kemudian dilakukannya perhitungan biaya berupa fix cost, variable cost, dan total cost. Tabel 6 merupakan gambaran biaya aktual secara keseluruhan yang terdiri dari biaya BBM, biaya KIR, biaya sopir dan kernet, dan biaya lemburan untuk sopir dan kernet.
Tabel 6. Total biaya pendistribusian secara aktual

\begin{tabular}{|c|c|c|c|}
\hline \multirow[b]{2}{*}{ Tanggal } & \multicolumn{3}{|c|}{ Biaya (Rp.) } \\
\hline & $\begin{array}{c}\text { Biaya BBM } \\
\text { (Variable Cost) }\end{array}$ & Fixed Cost & Total Cost \\
\hline 1 & 81.650 & 246.068 & 327.718 \\
\hline 2 & 115.988 & 246.068 & 362.056 \\
\hline 3 & 134.487 & 366.068 & 500.555 \\
\hline 4 & 94.085 & 246.068 & 340.153 \\
\hline 5 & 105.683 & 246.068 & 351.751 \\
\hline 6 & 111.090 & 246.068 & 357.158 \\
\hline 8 & 97.084 & 246.068 & 343.152 \\
\hline 9 & 122.420 & 306.068 & 428.488 \\
\hline 10 & 122.194 & 306.068 & 428.262 \\
\hline 11 & 104.586 & 246.068 & 350.654 \\
\hline 12 & 76.867 & 246.068 & 322.935 \\
\hline 13 & 119.204 & 306.068 & 425.272 \\
\hline 15 & 114.452 & 246.068 & 360.520 \\
\hline 16 & 100.031 & 246.068 & 346.099 \\
\hline 17 & 119.167 & 306.068 & 425.235 \\
\hline 18 & 116.715 & 306.068 & 422.783 \\
\hline 19 & 94.634 & 246.068 & 340.702 \\
\hline 20 & 144.219 & 366.068 & 510.287 \\
\hline 22 & 94.138 & 246.068 & 340.206 \\
\hline 23 & 118.402 & 306.068 & 424.470 \\
\hline 24 & 108.765 & 246.068 & 354.833 \\
\hline 25 & 90.994 & 246.068 & 337.062 \\
\hline 26 & 98.695 & 246.068 & 344.763 \\
\hline 27 & 123.635 & 306.068 & 429.703 \\
\hline 29 & 102.376 & 246.068 & 348.444 \\
\hline 30 & 103.325 & 246.068 & 349.393 \\
\hline 31 & 94.361 & 246.068 & 340.429 \\
\hline Total & 2.909.244 & 7.303 .836 & 10.213 .080 \\
\hline
\end{tabular}

Berikut ini merupakan contoh perhitungan biaya distribusi pada tanggal 3 Oktober 2018:

- Variable Cost

Biaya BBM $($ Variable Cost $)=$ $\frac{\operatorname{Jarak}(\mathrm{Km})}{\text { Rasio } B B M} x$ Harga Solar

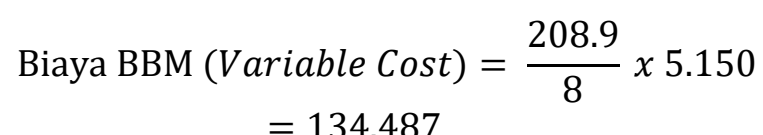

- Fix Cost Fix Cost = Biaya KIR /hari + Gaji Sopir /hari + Gaji Kernet /hari + Gaji Sopir Lembur /jam (jika lembur) + Gaji Kernet Lembur /jam (jika lembur) 


$$
\begin{array}{ll}
\text { Fix Cost } & =16.438+181.481+48.148+ \\
& 40.000(2 \text { jam })+20.000(2 \text { jam }) \\
& =\text { Rp. } 366.067 \\
\text { Total Cost } & =\text { Variable Cost }+ \text { Fix Cost } \\
& =134.487+366.067 \\
& =\text { Rp. } 500.555
\end{array}
$$

Pada Tabel 6 terdapat perbedaan untuk beberapa tanggal pada fix cost. Hal itu dikarenakan adanya jam lembur kerja pada supir dan kernetnya. Otomatis perusahaan memberikan biaya tambahan uang lembur untuk sopir dan kernetnya.

\section{Penentuan Rute Aktual}

Berikut ini adalah salah satu contoh gambaran rute awal tanggan 3 Oktober 2018 seperti terlihat pada Gambar 6.

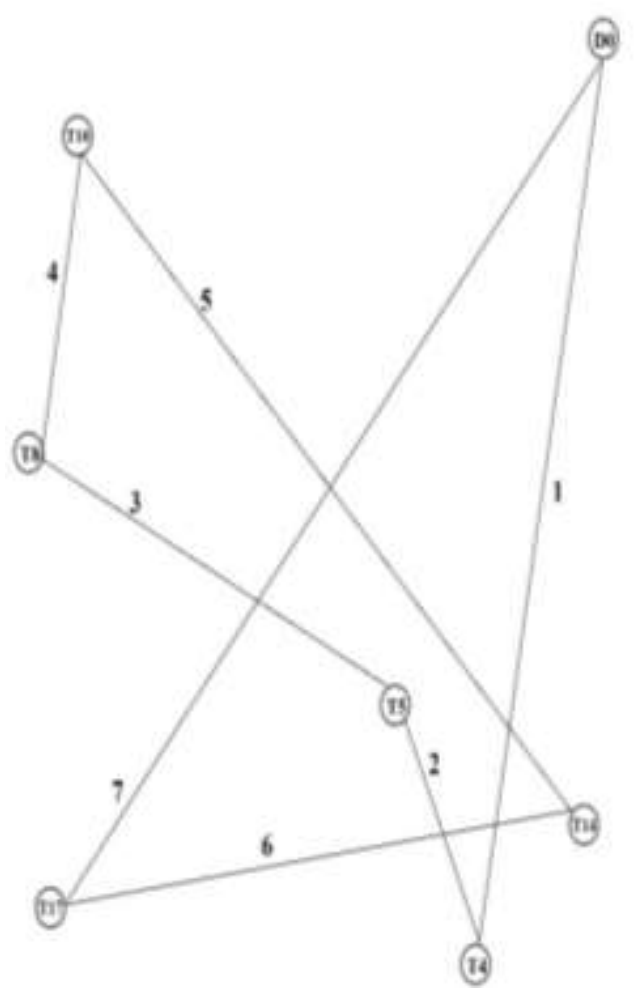

Gambar 2. Salah satu conto jaringan rute aktual pada tanggal 3 Oktober 2018

Dengan hasil perhitungan data aktual, maka dalam pada tanggal 3 Oktober 2018 perusahaan mengeluarkan total biaya pendistribusian sebesar Rp. 500.555 .

\section{Penentuan Jarak Menggunakan Metode Nearest Neighbor}

Data yang berisi total jarak yang ditempuh dari depot ke beberapa pelanggan dengan suatu rute terbaru seperti yang terjadi pada tanggal 3 Okrober 2018, awalnya rute yang dilalui harus dari depot toko 4 - toko 5- toko 8 - toko 10 - toko 14 - toko 17 - depot sekarang menjadi depot- toko 10- toko 8 toko 17 - toko 5 - toko 14- toko 4- depot sehingga dari rute yang terbaru total jarak yang ditempuh semakin pendek yaitu selisih jarak antara aktual dan nearest neighbor adalah $65,43 \mathrm{~km}$ dengan waktu tempuh semakin pendek yaitu 157,049 menit.

Proses penentuan rute menggunakan metode nearest neighbor dilakukan untuk mencari urutan rute baru yang akan ditempuh oleh armada pengiriman mobil box pada saat mendistribusikan produk. Rute yang baru diharapkan menjadi rute yang optimal daripada rute sebelumnya. Penjabaran total jarak tempuh dan total waktu tempuh yang diperoleh dari metode nearest neighbor diperlihatkan pada Tabel 7.

Tabel 7. Total jarak dan waktu tempuh

\begin{tabular}{cccc}
\hline Tanggal & Rute & $\begin{array}{c}\text { Total Jarak } \\
\text { (Km) }\end{array}$ & $\begin{array}{c}\text { Total } \\
\text { Waktu } \\
\text { Tempuh }\end{array}$ \\
\hline \hline 1 & $0-15-6-13-9-2-11-0$ & 85,70 & 253,68 \\
2 & $0-12-16-1-7-17-3-0$ & 116,50 & 325,60 \\
3 & $0-10-8-17-5-14-4-0$ & 143,48 & 385,67 \\
4 & $0-15-6-13-2-7-10-0$ & 108,25 & 304,47 \\
5 & $0-12-18-9-1-11-3-0$ & 125,80 & 361,58 \\
6 & $0-16-5-14-4-7-8-0$ & 132,50 & 364,67 \\
8 & $0-16-6-9-2-8-14-0$ & 122,65 & 340,36 \\
9 & $0-10-1-14--5-18-3-0$ & 135,30 & 371,39 \\
10 & $0-15-6-16-11-14-4-0$ & 135,13 & 371,65 \\
11 & $0-12-16-13-18-7-17-0$ & 102,69 & 293,78 \\
12 & $0-15-1-11-10-8-3-0$ & 116,53 & 326,33 \\
13 & $0-12-5-14-4-9-17-0$ & 148,39 & 401,46 \\
15 & $0-6-13-2-8-10-17-0$ & 139,56 & 381,62 \\
16 & $0-16-9-1-14-7-3-0$ & 125,43 & 344,35 \\
17 & $0-15-6-18-4-17-11-0$ & 132,40 & 365,76 \\
18 & $0-12-13-5-2-8-17-0$ & 118,48 & 331,01 \\
19 & $0-16-9-1-10-3-7-0$ & 129,33 & 356,38 \\
20 & $0-15-6-14-4-17-8-0$ & 135,60 & 372,11 \\
22 & $0-12-13-5-9-2-11-0$ & 89,93 & 262,49 \\
23 & $0-16-1-10-3-17-7-0$ & 122,20 & 339,95 \\
24 & $0-15-6-18-9-14-4-0$ & 114,60 & 323,04 \\
25 & $0-11-10-2-8-13-5-0$ & 113,45 & 319,61 \\
26 & $0-12-16-9-1-10-3-0$ & 121,20 & 330,88 \\
27 & $0-15-11-7-17-5-4-0$ & 146,97 & 396,72 \\
29 & $0-12-6-18-2-8-14-0$ & 112,05 & 314,92 \\
30 & $0-9-13-7-3-1-10-0$ & 129,18 & 351,37 \\
31 & $0-12-15-13-18-5-4-0$ & 99,03 & 283,68 \\
\hline & TOTAL & $\mathbf{3 . 3 0 2}$ & $\mathbf{9 . 1 7 5}$ \\
\hline & & & \\
\hline
\end{tabular}




\section{Biaya Pendistribusian Dengan Metode Nearest Neighbor}

Selanjutnya dilakukan perhitungan biaya berupa fix cost, variable cost, dan total cost. Dengan rute baru, mampu meminimasi biaya pendistribusian produk yang dikeluarkan oleh perusahaan. Berikut adalah Tabel 8 yang berisikan rekapitulasi data biaya pendistribusian nearest neighbor.

Tabel 8. Biaya pendistribusian dari hasil nearest

\begin{tabular}{|c|c|c|c|}
\hline \multirow[b]{2}{*}{ Tanggal } & \multicolumn{3}{|c|}{ B iaya (Rp.) } \\
\hline & $\begin{array}{c}\text { Biaya BBM } \\
(\text { Variable Cost })\end{array}$ & $\begin{array}{c}\text { Fixed } \\
\text { Cost }\end{array}$ & Total Cost \\
\hline 1 & 55.169 & 246.068 & 301.237 \\
\hline 2 & 74.997 & 246.068 & 321.065 \\
\hline 3 & 92.362 & 246.068 & 338.430 \\
\hline 4 & 69.686 & 246.068 & 315.754 \\
\hline 5 & 80.984 & 246.068 & 327.052 \\
\hline 6 & 85.297 & 246.068 & 331.365 \\
\hline 8 & 78.956 & 246.068 & 325.024 \\
\hline 9 & 87.099 & 246.068 & 333.167 \\
\hline 10 & 86.992 & 246.068 & 333.060 \\
\hline 11 & 66.105 & 246.068 & 312.173 \\
\hline 12 & 75.013 & 246.068 & 321.081 \\
\hline 13 & 95.524 & 246.068 & 341.592 \\
\hline 15 & 89.843 & 246.068 & 335.911 \\
\hline 16 & 80.742 & 246.068 & 326.810 \\
\hline 17 & 85.233 & 246.068 & 331.300 \\
\hline 18 & 76.268 & 246.068 & 322.336 \\
\hline 19 & 83.253 & 246.068 & 329.321 \\
\hline 20 & 87.293 & 246.068 & 333.360 \\
\hline 22 & 57.889 & 246.068 & 303.957 \\
\hline 23 & 78.666 & 246.068 & 324.734 \\
\hline 24 & 73.774 & 246.068 & 319.842 \\
\hline 25 & 73.033 & 246.068 & 319.101 \\
\hline 26 & 78.023 & 246.068 & 324.090 \\
\hline 27 & 94.610 & 246.068 & 340.678 \\
\hline 29 & 72.132 & 246.068 & 318.200 \\
\hline 30 & 83.161 & 246.068 & 329.229 \\
\hline 31 & 63.753 & 246.068 & 309.821 \\
\hline Total & 2.125 .858 & 6.643 .836 & 8.769 .693 \\
\hline
\end{tabular}

Contoh Perhitungan Tanggal 3 Oktober 2018.

- Variable Cost

$$
\text { Biaya BBM (Variable Cost) }
$$$$
=\frac{\operatorname{Jarak}(\mathrm{Km})}{\operatorname{Rasio} B B M} \times \text { Harga Solar }
$$

Biaya BBM $($ Variable Cost $)=\frac{208,9}{8} \times 5,1$
$=R p 92.362$

- Fix Cost

Fix Cost = Biaya KIR /hari + Gaji Supir /hari + Gaji Kernet /hari + Gaji Supir Lembur /jam (jika lembur)
+ Gaji Kernet Lembur /jam (jika lembur)

$$
\begin{aligned}
\text { Fix Cost } & =16,438+181,481+48,148 \\
\text { Total Cost } & =246,068 \\
& =R p 92.362+\operatorname{Rp} 246,068 \\
& =\operatorname{Rp} 338.430
\end{aligned}
$$

\section{Penentuan Rute Hasil Nearest Neighbor}

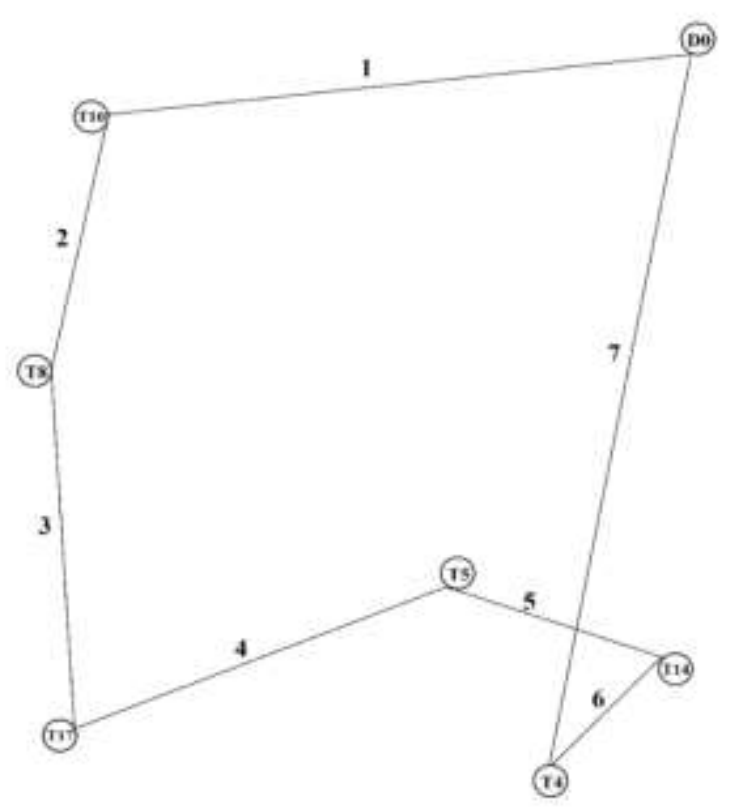

Gambar 3. Jaringan rute distribusi nearest neighbor

Pada gambar 3 diatas merupakan jaringan rute pendistribusian yang baru dimana pada tanggal 3 Oktober 2018 yaitu $D_{0} \rightarrow T_{10} \rightarrow T_{8} \rightarrow T_{17} \rightarrow T_{5} \rightarrow$ $T_{14} \rightarrow T_{4} \rightarrow D_{0}$ Dengan total jarak tempuh sebesar $143.5 \mathrm{~km}$. Dengan total biaya yang dikeluarkan Rp. 338.430. Biaya-biaya ini merupakan biaya distribusi yang dihasilkan dari rute terbaru, dimana biaya yang didapatkan jauh lebih murah daripada menggunakan rute yang lama.

\section{Analisa}

Tabel 9. Perbandingan data aktual dan data nearest

\begin{tabular}{cccccc}
\hline \multicolumn{3}{c}{ neighbor } \\
\hline \multirow{3}{*}{ Data Altual } & \multicolumn{4}{c}{ Nearest Neighbor } \\
\hline \multirow{2}{*}{ Total Jarak Total Waltu } & Rute & $\begin{array}{c}\text { Total Jarak } \\
(\mathrm{Km})\end{array}$ & Total Waku \\
& $(\mathrm{Km})$ & Tempuh & & Tempuh \\
\hline \hline $0-4-5-8-10-14-17-0$ & 208,91 & 542,7 & $0-10-8-17-5-14-4-0$ & 143,48 & 385,7 \\
\hline
\end{tabular}

Tabel 9 menjelaskan contoh perbandingan perbandingan rute, total jarak, dan total waktu pada tanggal 3 Oktober 2018. Pada Tabel 10 terlihat bahwa jarak yang ditempuh dengan menggunakan 
nearest neighbor jauh lebih kecil dari 208,91 km menjadi 143,48 $\mathrm{km}$ dan begitu sebaliknya untuk total waktu yang ditempuh semakin pendek dari 542,7 menjadi 385,7. Dari perhitungan ini dapat disimpulkan bahwa metode Nearest Neighbor mampu meminimumkan jarak tempuh dan total waktu yang ditempuh.

Tabel 11 di bawah ini merupakan perbandingan biaya distribusi pada tanggal 3 Oktober 2018. Dengan adanya rute terbaru maka biaya juga dapat diminimalkan, hal ini dapat terlibat pengurangan biaya dari semula biaya distribusi keseluruhan adalah Rp. 500.555 saat ini menjadi Rp. 338.430

Tabel 11. Biaya distribusi nearest neighbor

\begin{tabular}{cccccc}
\hline \multicolumn{3}{c}{ Data Altual } & \multicolumn{4}{c}{ Nearest Neighbor } \\
\hline $\begin{array}{cccccc}\text { Fix Cost } \\
(\text { Rp. })\end{array}$ & Variable & Total Cost & Fix Cost & Variable & Total Cost \\
\hline \hline 366.068 & 134.487 & (Rp.) & (Rp.) & Cost (Rp.) & (Rp.) \\
\hline
\end{tabular}

Dapat dilihat pada Tabel 11, dijelaskan bahwa variable cost data aktual lebih besar dibandingkan dengan metode $\mathrm{NN}$, dikarenakan dengan total jarak kendaraan sudah berbeda. Jika semakin besar total jarak yang ditempuh maka semakin besar biaya BBM (variable cost) yang dikeluarkan oleh perusahaan. Kemudian untuk fix cost juga didapatkan perbedaan biayanya, hal ini dikarenakan pada data aktual terdapat biaya lembur pada supir dan kernet. Pada perhitungan menggunakan metode NN, karena total waktu distribusi pada tanggal 3 Oktober 2018 sebesar 385,6 menit tidak melebihi waktu kerja normal yaitu selama 480 menit, maka tidak terjadinya waktu lembur, yang otomatis tidak adanya biaya lembur pada supir dan kernetnya.

Berikut Tabel 12 adalah perbandingan rute distribusi produk FMCG yang dilakukan oleh PT. XYZ selama Bulan Oktober 2018 yaitu:

Tabel 12. Perbedaan total jarak dan total biaya selama bulan Oktober 2018

\begin{tabular}{|c|c|c|c|c|}
\hline \multirow{2}{*}{ Tanggal } & \multicolumn{2}{|c|}{ Total Jarak (Km) } & \multicolumn{2}{|c|}{ Total Cost (Rp.) } \\
\hline & Data Aktual & Nearest Neighbor & Data Aktual & Nearest Neighbor \\
\hline 1 & 126.84 & 85.70 & $327,718.02$ & $301,237.36$ \\
\hline 2 & 180.18 & 116.50 & $362,055.77$ & $321,064.86$ \\
\hline 3 & 208.91 & 143.48 & $500,555.41$ & $338,430.02$ \\
\hline 4 & 146.15 & 108.25 & $340,153.12$ & $315,753.92$ \\
\hline 5 & 164.17 & 125.80 & $351,750.79$ & $327,051.74$ \\
\hline 6 & 172.57 & 132.50 & $357,157.78$ & $331,364.86$ \\
\hline 8 & 150.81 & 122.65 & $343,151.92$ & $325,023.92$ \\
\hline 9 & 190.17 & 135.30 & $428,488.29$ & $333,167.36$ \\
\hline 10 & 189.82 & 135.13 & $428,262.46$ & $333,060.07$ \\
\hline 11 & 162.46 & 102.69 & $350,653.60$ & $312,173.06$ \\
\hline 12 & 119.40 & 116.53 & $322,934.55$ & $321,080.95$ \\
\hline 13 & 185.17 & 148.39 & $425,271.71$ & $341,592.44$ \\
\hline 15 & 177.79 & 139.56 & $360,519.76$ & $335,911.35$ \\
\hline 16 & 155.39 & 125.43 & $346,098.82$ & $326,810.33$ \\
\hline 17 & 185.11 & 132.40 & $425,234.54$ & $331,300.49$ \\
\hline 18 & 181.30 & 118.48 & $422,782.54$ & $322,336.27$ \\
\hline 19 & 147.00 & 129.33 & $340,702.05$ & $329,320.95$ \\
\hline 20 & 224.03 & 135.60 & $510,286.76$ & $333,360.49$ \\
\hline 22 & 146.23 & 89.93 & $340,205.69$ & $303,957.20$ \\
\hline 23 & 183.93 & 122.20 & $424,469.83$ & $324,734.24$ \\
\hline 24 & 168.95 & 114.60 & $354,832.61$ & $319,841.74$ \\
\hline 25 & 141.35 & 113.45 & $337,062.05$ & $319,101.42$ \\
\hline 26 & 153.31 & 121.20 & $344,763.04$ & $324,090.49$ \\
\hline 27 & 192.05 & 146.97 & $429,702.86$ & $340,677.78$ \\
\hline 29 & 159.03 & 112.05 & $348,444.47$ & $318,200.17$ \\
\hline 30 & 160.50 & 129.18 & $349,392.67$ & $329,228.99$ \\
\hline 31 & 146.58 & 99.03 & $340,428.71$ & $309,820.69$ \\
\hline TOTAL & 4519.21 & 3302.30 & $10,213,079.81$ & $8,769,693.16$ \\
\hline
\end{tabular}


Tabel 12 diatas merupakan rekapitulasi perhitungan biaya dilakukan dengan jumlah jarak tempuh rute. Tujuan dari ini adalah untuk membandingkan perhitungan mana yang lebih baik sehingga cost yang dikeluarkan oleh perusahaan tidak besar untuk melakukan pendistribusian. Dengan perhitungan variabel yang tidak menentu dan dipengaruhi berbagai faktor tertentu yaitu adalah jumlah jarak yang dimana mampu mempengaruhi biaya pengeluaran untuk BBM. Selain itu juga jika dalam melakukan pendistribusian memakan waktu lebih lama dibanding jam kerja supir, maka diadakannya jam lembur untuk supir dan kernetnya, alhasil pengeluaran biaya lagi dalam penggajian supir dan kernet tersebut.

Biaya transportasi sangat berpengaruh dalam jarak tempuh yang dihasilkan oleh metode tertentu. Dengan menggunakan metode nearest neighbor yang digunakan dalam penentuan rute pendistribusian sangat mempengaruhi biaya transportasi.

Pada total cost yang harus dikeluarkan perusahaan pada bulan Oktober 2018, dengan menggunakan nearest neighbor perbedaan dalam total cost sebesar Rp. 1.443.386 lebih rendah dibanding data aktual. Dengan menggunakan metode Nearest Neighbor dianggap metode yang tepat untuk menyelesaikan permasalahan yang ada karena metode ini menggunakann pembentukan rute yang baik dimana mampu meminimasi jarak yang sangat mempengaruhi

\section{KESIMPULAN}

Berdasarkan hasil penentuan rute menggunakan nearest neighbor, mampu meminimasi total jarak pendistribusian produk FMCG yang dilakukan oleh PT XYZ pada bulan oktober sebesar $27 \%$ atau 44,09 $\mathrm{km}$ tiap harinya dan mampu menghemat total biaya $15 \%$ atau Rp. 53.458 setiap harinya serta mengurangi total waktu tempuh 157 menit dari data aktual ke data nearest neighbor. Dengan demikian dapat disimpulkan bahwa penentuan rute nearest neighbor dapat mengurangi total jarak tempuh, total waktu dan biaya distribusi.
Untuk penelitian selanjutnya, perlunya dibangun suatu sistem berbasis applikasi yang membantu pengendara dalam menentukan jalur alternatif ke beberapa pelanggan apabila terjadi suatu kendala. Dan perlunya ada tambahan sensor yang nantinya diletakkan di armada sebagai pendeteksi jumlah muatan yang telah terisi di armada agar tidak terjadi kelebihan muatan dan meminimalisir kecelakaan.

\section{REFERENSI}

[1] A. Aliyuddin, P. S. Puspitorini and M. Muslimin, "Metode Vehicle Routing Problem (VRP) dalam Mengoptimalisasikan Rute Distribusi Air minum PT. SMU," Seminar Nasional Teknik Industri, Surabaya, 2017.

[2] P. Toth and D. Vigo, The Vehicle Routing Problem, Philadelphia: SIAM, 2002.

[3] W. Prasetyo and M. Tamyiz, "Vehicle Routing Problem dengan Aplikasi Metode Nearest Neighbor," Journal of Research and Technology, Vol. 3, No. 2, pp. 88-99, 2017.

[4] O. Braysy and M. Gendreau, "Vehicle Routing Problem with Time Windows, Part I: Route Construction and Local Search Algorithms," System Operations Research and Technology, Vol. 39, pp. 104-118, 2005.

[5] L. Leymena, B. W. C. Suryo, Yuniaristanto and W. Sutopo, "Analisis Penentuan Rute Distribusi Menggunakan Metode," Seminar dan Konferensi Nasional IDEC 2019, Surakarta, 2019. 